\title{
The Detection of Incipient Caries with Tracer Dyes
}

\author{
W.J. O'BRIEN, L. VAZQUEZ, and W.M. JOHNSTON
}

University of Michigan, School of Dentistry, Ann Arbor, Michigan 48109-1078

\begin{abstract}
The purpose of this study was to determine the increase in color contrast produced by the use of a tracer dye in detection of incipient caries lesions with transillumination.

Twenty-four caries-free first premolars were immersed in an acid gelatin for production of artificial incipient caries lesions. After the lesions had developed, these teeth were photographed by transillumination. Two photographs were taken of each tooth. The first photograph showed the lesion without dye. A blue tracer dye was then added and absorbed by the lesion, and a second photograph was taken. The data on the color difference were obtained by use of a reflectance colorimeter and showed a four-fold increase between the lesion and surrounding area with the dye. A two-way analysis of variance was used for the statistical interpretation. The color difference between the lesion without the dye and then with the dye was significant. The use of the blue tracer dye, therefore, significantly increased the contrast in the images of the artificial incipient lesions.
\end{abstract}

J Dent Res 68(2):157-158, February, 1989

\section{Introduction.}

Transillumination has been used for diagnosis in dentistry for many years. It has the advantage that it is more sensitive in detecting incipient caries, fractures, and calculus than is radiography. At present, several diagnostic devices are available that utilize fiber optic transillumination (FOTI).

Results of previous studies regarding dental caries detection by fiber optic transillumination (FOTI) have been conflicting. Several studies suggested that FOTI can detect caries lesions more accurately than radiography (Bomba, 1971; Friedman and Marcus, 1971). Other investigators indicated that FOTI has more limited sensitivity (Barenie et al., 1973; Reynolds and Aduddel, 1971; Taylor et al., 1967; Winter and Fiaschette, 1949; Wright and Simon, 1972). All of these studies were limited to existing lesions without any standardization of lesion depth. There was also no standardization of the ambient lighting conditions and other operating procedures between these studies. Parker et al. (1981) showed that FOTI was more sensitive than radiography in detecting artificial incipient lesions with an average depth of $164 \mu \mathrm{m}$. O'Brien et al. (1983) demonstrated that blue polymer curing lights were useful for diagnostic transillumination. Dyes have been used for many years to enhance caries detection. As early as 1940, Gomori used silver nitrate to stain caries lesions. Other investigators examined the value of 8-hydroxyquinoline in the detection of early caries (Konikoff and Lyles, 1966). Fluorescein dye has been used in the detection of caries lesions by use of ultraviolet illumination (Hefferren et al., 1971). A solution of basic fuchsin in propylene glycol has been used both in the diagnosis and treatment of caries lesions (Fusayama, 1979, 1980).

The purpose of this research was to determine whether use of a blue dye would enhance the image produced by FOTI in detection of incipient caries.

Received for publication August 18, 1987

Accepted for publication October 14, 1988

This study was supported in part by research grant DE02731 from the National Institute of Dental Research, National Institutes of Health, Bethesda, MD 20892.

\section{Materials and methods.}

Artificial incipient lesions were produced with the Silverstone acid gel method in 17 sound extracted teeth (Silverstone, 1966). These lesions were photographed by means of a tungsten light FOTI device (Novar Fiber Optic Unit, Demetron Research Corp., Danbury, CT) with color negative film [ET 136-36 ASA (tungsten), Eastman Kodak Co., Rochester, NY]. A drop of a $10 \%$ aqueous solution of dye (Brilliant Blue FCF, Hilton-Davis, Cincinnati, $\mathrm{OH}$ ) was then applied to the artificial lesions. This dye is also known as FD\&C Blue No. 1 and is widely used as a food dye. The lesions were photographed again with the same arrangement. Prints were made from the color negatives, and a colorimeter was used to analyze for color differences between the lesion and surrounding tooth structure areas (Hunter Tristimulus Colorimeter, Model D25A$Z$, Hunter Associates, Inc., Reston, VA 22090). From the photographs, we obtained CIE tristimulus values of the lesion and surrounding tooth structure areas. These data were then used for calculation of $\mathrm{CIE} \mathrm{L*a*b*}$ color difference values, designated as $\Delta \mathrm{E}$. After photography, the teeth were sectioned and the depth of each artificial lesion was measured with an optical microscope.

\section{Results.}

The measured depths of the artificial lesions had an average value of $174 \mu \mathrm{m}$. The dye was readily absorbed by the porous artificial white spots, greatly increasing the color contrast, as shown by the color difference values given in Table 1 . With the dye, the CIE L*a*b* color difference between the lesions and the surrounding tooth structure was increased by a factor of 3.7. The analysis of variance is presented in Table 2. The variance ratio between the teeth with and without tracer dye was significant at the 0.001 level. An approximal view of one of the teeth before and after application of the tracer dye is

TABLE 1

$\triangle E\left(L^{*} a^{*} b^{*}\right)$ VALUES OBTAINED FOR EACH TOOTH'S COLOR DIFFERENCE WITH AND WITHOUT TRACER DYE

\begin{tabular}{ccc}
\hline Tooth No. & Without Dye & With Dye \\
\hline 2 & 2.0 & 53.9 \\
3 & 6.9 & 51.9 \\
5 & 9.1 & 55.5 \\
6 & 22.2 & 71.4 \\
10 & 53.1 & 102.4 \\
11 & 32.2 & 73.9 \\
12 & 30.0 & 95.8 \\
13 & 23.0 & 73.2 \\
14 & 3.0 & 75.7 \\
16 & 7.1 & 75.0 \\
17 & 33.0 & 68.0 \\
19 & 20.0 & 61.0 \\
20 & 9.1 & 90.5 \\
21 & 46.7 & 90.5 \\
22 & 13.0 & 68.7 \\
23 & 13.0 & 68.7 \\
24 & 18.1 & 84.0 \\
AVERAGE & 20.1 & 73.2 \\
\hline
\end{tabular}


TABLE 2

ANALYSIS OF VARIANCE OF COLOR DIFFERENCES WITH AND WITHOUT TRACER DYES

\begin{tabular}{lrrc}
\hline \hline Source of Variation & df & MS & F \\
\hline Between Teeth & 16 & 364 & 5.6 \\
Between FOTI Methods & 1 & 24590 & $376^{*}$ \\
Error & 16 & 66 & - \\
\hline
\end{tabular}

*Significant at 0.001 level.
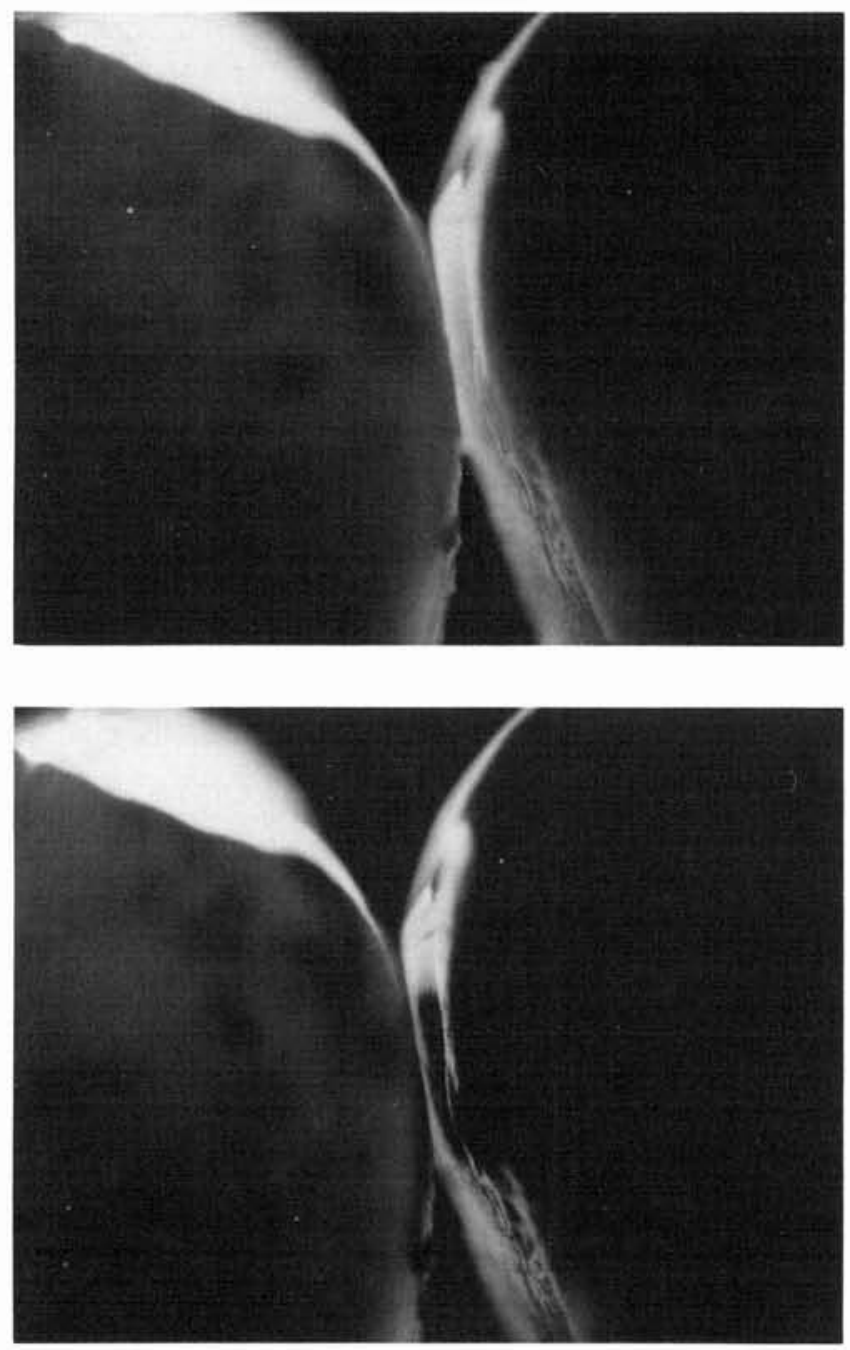

Fig.-(top) Transillumination of two extracted teeth in contact. The enamel of the tooth on the right has an artificial incipient lesion. (bottom) Transillumination of the teeth shown in (top) with the use of blue tracer dye. shown in the Fig. The location of the artificial lesion can be clearly seen, since yellow tungsten light is absorbed by the blue dye.

\section{Discussion.}

The use of a tracer dye to increase the contrast between artificial white spots and the surrounding tooth structure takes advantage of the porous structure of demineralized tissue. The appearance of the lesions is enhanced with FOTI. Optical theory indicates that the absorption of light by the dye will be maximum when the color of the dye is the complementary color of the light color. In this study, the tungsten light is yellow and the dye was blue. The results show promise as a means of improving the detection of caries with transillumination.

\section{REFERENCES}

BARENIE, J.; LESKE, G.; and RIPA, L.W. (1973): The Use of Fiber Optic Transillumination for Detection of Proximal Caries, Oral Sung 36:891-897.

BOMBA, J.L. (1971): Fiber Optic Lighting Systems: Their Role in Dentistry, Dent Clin N Am 15:197-218.

FRIEDMAN, J. and MARCUS, M.I. (1971): Transillumination of the Oral Cavity with the Use of Fiber Optics, J Am Dent Assoc 80:801-809.

FUSAYAMA, T. (1979): Two Layers of Carious Dentin: Diagnosis and Treatment, Oper Dent 4:63-70.

FUSAYAMA, T. (1980): New Concepts in Operative Dentistry, Chicago: Quintessence Pub. Co., Inc.

GOMORI, L.A. (1940): A Method for Staining of Carious Lesions in Teeth, Proc Soc Exp Biol Med 44:250-253.

HEFFERREN, J.J.; COOLEY, R.O.; HALL, J.B.; OLSEN, N.H.; and LYON, H.W. (1971): Use of Ultraviolet Illumination in Oral Diagnosis, J Am Dent Assoc 82:1353-1360.

KONIKOFF, B. and LYLES, G.R. (1966): "In vivo" Method for Detection of Soluble Calcium in Enamel and Its Developmental Philosophy, J Louisiana Dent Assoc 24:5-11.

O'BRIEN, W.J.; YEE, J., Jr.; DENNISON, J.B.; JOHNSTON, W.M.; STEFANSKI, R.; YEE, W.J.; and FANIAN, F. (1983): The Application of Blue Polymer Curing Lights for Diagnostic Transillumination, $J$ Am Dent Assoc 106:839-842.

PARKER, P.J.; O'BRIEN, W.J.; and BROOKS, S.L. (1981): Detection of Enamel Demineralization with Transillumination, J Clin Prev Dent 3:12-14.

REYNOLDS, R.L. and ADUDDEL, A.C. (1971): A Clinical Evaluation of Fiber Optics in Diagnosis, J S Calif Dent Assoc 39:869900.

SILVERSTONE, L.M. (1966): The Primary Translucent Zone of Enamel Caries and of Artificial Caries-like Lesions, Br Dent $J$ 120:461-471.

TAYLOR, W.J.; WARE, W.H.; and McDOWELL, J.A. (1967): Illumination of the Oral Cavity, J Am Dent Assoc 74:1207-1209.

WINTER, G.R. and FIASCHETTE, F.J. (1949): Transillumination of the Oral Cavity, Dent Digest 55:106-110.

WRIGHT, G.Z. and SIMON, I. (1972): An Evaluation of Transillumination for Caries Detection in Primary Molars, J Dent Child 39:199-202. 